\title{
Crossing the equator: a northern occurrence of the pygmy right whale
}

Cheng-Hsiu Tsai ${ }^{1 *}$ (D) and James G. Mead ${ }^{2}$

\begin{abstract}
Here we document the first stranding record of the pygmy right whale in the Northern Hemisphere-on the coast of The Gambia, Africa (NE Atlantic Ocean, around latitude $13^{\circ} \mathrm{N}$ ) - -a location in stark contrast to its current distribution exclusively south of the equator. The original specimen is now missing and untraceable, but a photo found in the files of the Marine Mammal Program, Smithsonian Institution shows sufficient diagnostic features that allow it to be taxonomically identified as the pygmy right whale, Caperea marginata, including: small body size; streamlined overall body shape; generally dark skin coloration; arched rostrum along the lateral margin; triangular and narrow rostrum in dorsal view; lack of head callosities; some fringes on the dorsal surface of the tongue; small and relatively posteriorly positioned dorsal fin; and small and dark-colored flipper. On the whole, a stranding of the pygmy right whale in the Northern Hemisphere, although likely to be a chance event, calls for more detailed studies of how climate change and ocean currents affect the evolution and distribution (re-patterning) of marine mammals and, ultimately, the entire marine ecosystem.
\end{abstract}

Keywords: Cetacea, Mysticeti, Biogeography, Stranding

\section{Introduction}

The pygmy right whale Caperea marginata (Cetacea: Mysticeti) is one of the least known large and extant vertebrate species, due to its elusive nature and comparatively restricted distribution in the Southern Hemisphere $[1,2]$. Similarly, Caperea-like fossils are extremely scarce and also mainly found in the Southern Hemisphere [3-5], except for two recent reports of fossil Caperea from the Pleistocene of Japan and Italy, respectively [6], indicating a more complicating scenario for the origin and evolution of marine mammal distribution. Here we document the first stranding of the extant pygmy right whale in the Northern Hemisphere - on the coast of The Gambia, Africa (NE Atlantic Ocean, around latitude $13^{\circ} \mathrm{N}$ ).

\section{Material and methods}

The Gambia whale was found stranded on the beach in January 1995. Bengt Larsen photographed the specimen, as shown in Fig. 1 (the exact locality is unknown). Subsequently, Tom Arnbom (Department of Zoology, Stockholm

\footnotetext{
* Correspondence: whaletsai@ntu.edu.tw; craniata@gmail.com

1Department of Life Science, National Taiwan University, Taipei 10617,

Taiwan

Full list of author information is available at the end of the article
}

University) mailed the photo to JGM asking for identification (see the original mail from Tom Arnbom to JGM indicating that this individual was found on the beach of The Gambia in 1995 in the Supporting Information). It seems that the stranded specimen is now missing and untraceable; the record could be found in the files of the Marine Mammal Program, Smithsonian Institution, and its identification number is STR14661 in the Cetacean Distributional Database, Department of Vertebrate Zoology, National Museum of Natural History, Smithsonian Institution, Washington DC, USA.

\section{Results}

The photo (Fig. 1) shows sufficient diagnostic features to identify the Gambia whale as the pygmy right whale Caperea marginata [1, 2, 7]:

(1) small body size; assuming a height of $170 \mathrm{~cm}$ for the person on the left (Fig. 1a), we estimate the total length of the Gambia whale to be $270 \mathrm{~cm}$;

(2) the overall body shape is streamlined;

(3) the dorsal side of the body is generally dark-colored;

(4) the rostrum is arched along its lateral margin (as illustrated in Fig. 1b); 


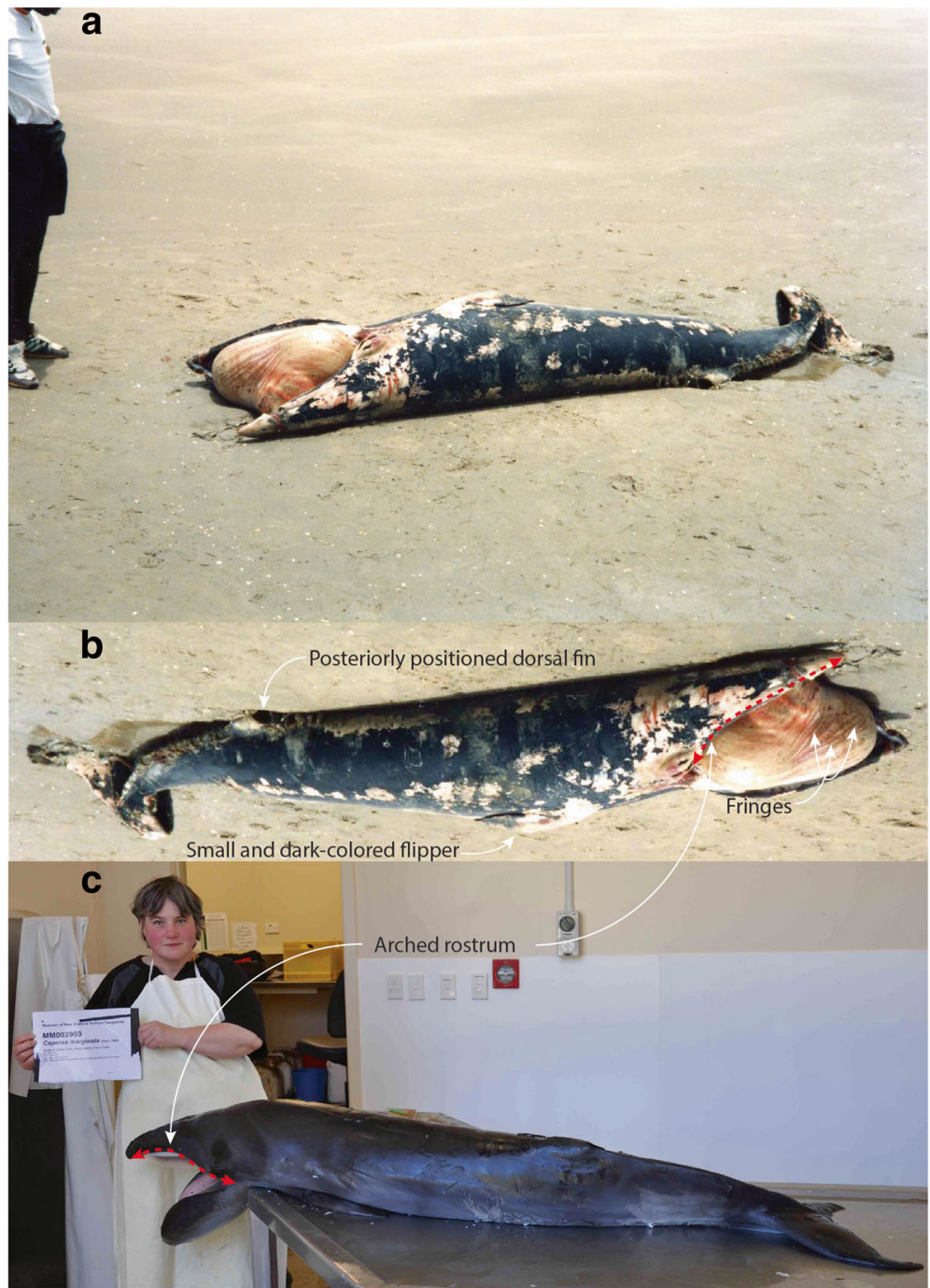

Fig. 1 A pygmy right whale Caperea marginata from The Gambia, Africa. a The original photo of the Gambia Caperea by Bengt Larsen in the files of Marine Mammal Program, Department of Vertebrate Zoology, Smithsonian Institution; (b) The same image, edited to facilitate taxonomic comparisons (mirror image of (a)). c A stillborn C. marginata NMNZ MM002959 from New Zealand for comparison (photo by (HT). A key diagnostic feature, arched rostrum, is illustrated. NMNZ, National Museum of New Zealand (Te Papa Tongarewa), Wellington, New Zealand

(5) triangular and narrow rostrum in dorsal view;

(6) lack of head callosities;

(7) some fringes on the dorsal surface of the tongue;

(8) small and relatively posteriorly positioned dorsal fin;

(9) small and dark-colored flipper (the skin of the proximal half had worn off).

Other diagnostic features of the pygmy right whale $[1,2,7]$, including distinctive crescent-shaped pale shadings located circumferentially near the head region, a prominent median notch of the fluke, and the presence of mandibular and maxillary hairs, could not be clearly observed due to the limited visual information (only a single photo showing a dorsolateral view from the right side, as shown in Fig. 1a, b) and the preservation of the specimen (scars and rotting).

\section{Discussion}

Previously, the northern-most occurrence of the pygmy right whale was at $19^{\circ} \mathrm{S}$ (Fig. 2); an atypical sighting, likely due to drifting along the Benguela Current [2]. Our new specimen represents the first record of the extant pygmy right whale in the Northern Hemisphere (Fig. 1, NE Atlantic Ocean, around latitude $13^{\circ} \mathrm{N}$, mirroring the recent description of the first Caperea fossils from north of the equator [6]). It remains uncertain whether this Gambia occurrence is simply a chance event, such as an already dead animal drifting northwards with the Benguela 


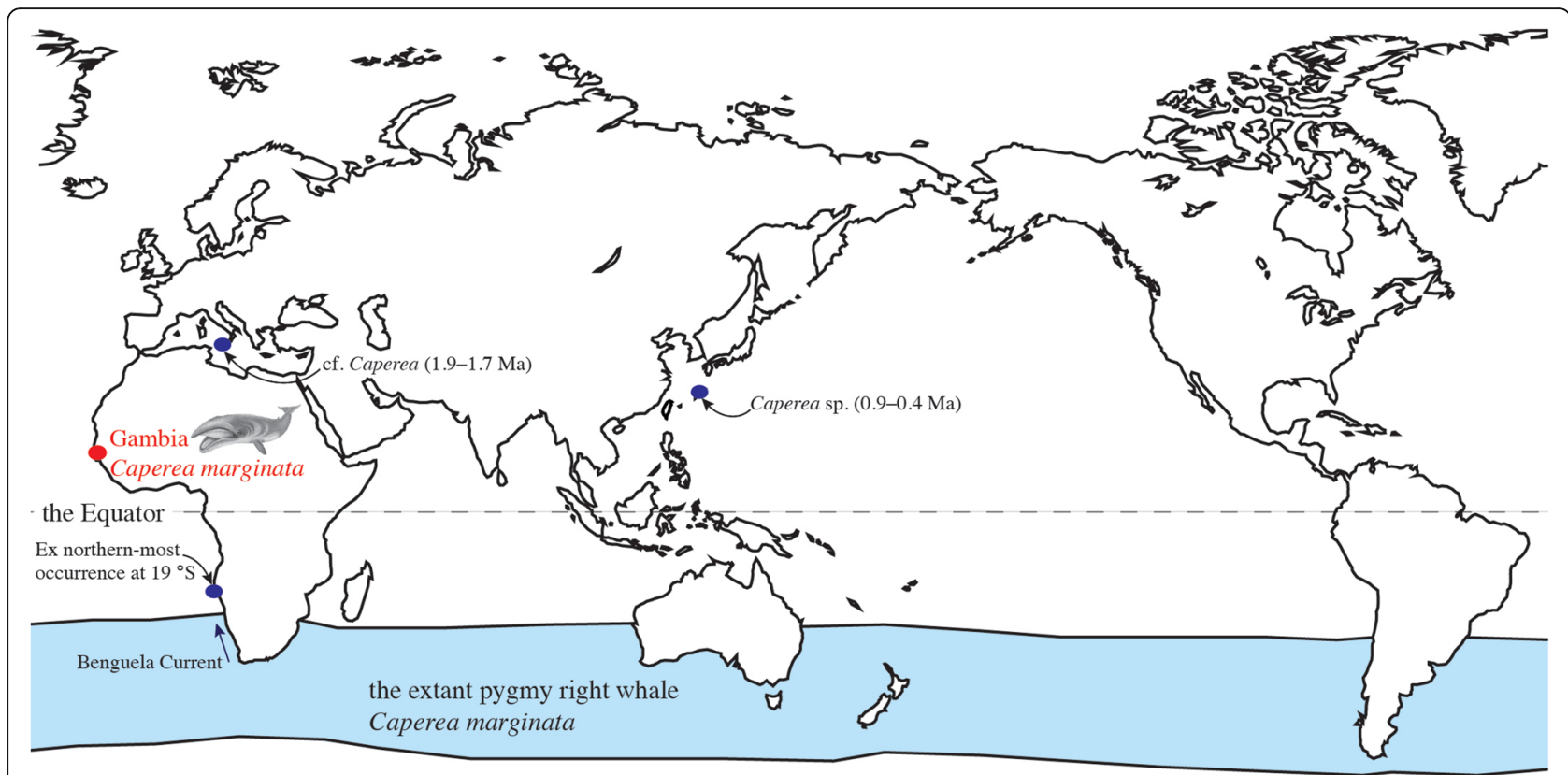

Fig. 2 Proposed distribution of the pygmy right whale (in light blue, modified from Kemper, 2014), extralimital occurrence at $19^{\circ} \mathrm{S}$, Pleistocene occurrences in the Northern Hemisphere (blue circles; Ma: million years), and the occurrence of the Gambia Caperea (in red; Caperea illustration by Moyna Müller)

Current, ultimately washing up in The Gambia. This scenario seems more plausible than the animal actively crossing the equator, given its small size $(270 \mathrm{~cm})$ and, thus, rather young age. Newborn Caperea are around $200 \mathrm{~cm}$ in length $[1,2]$, suggesting that the Gambia whale was a young calf (less than one year old) without sufficient swimming skills for crossing the equator. Had the animal been alive during the journey, it would likely have been accompanied by its mother or a small pod; however, since 1995 (the stranding year), no other northern occurrences of Caperea reported.

Like the pygmy right whale, the gray whale Eschrichtius robustus is restricted to a single hemisphere - in this case, the North Pacific, with the North Atlantic population having gone extinct in the eighteenth century [8]. Likewise, all known fossil eschrichtiids are also from the Northern Hemisphere [9-14]. Yet, there was a single sighting of a gray whale in the Southern Hemisphere [15] - in Namibia, around latitude $13^{\circ} \mathrm{S}$. This remarkable extralimital occurrence is comparable to the Gambia Caperea and, along with additional examples of equatorial crossings by other mysticete species $[16,17])$, suggesting that faunal exchange between both hemispheres may be more frequent, or may be in the process of becoming more frequent, than commonly thought. Together, records such as these invite more detailed studies of how climate change and ocean currents affect the evolution and distribution of marine mammals in the context of the wider marine ecosystem [18]. In addition, they emphasize the importance of research on remote and often ignored regions for a more comprehensive picture of global changes from the past to the present and the future.

\section{Conclusions}

Despite being a single, and likely a chance event, the first stranding of a pygmy right whale in the Northern Hemisphere is significant given the usual restriction of this species to the Southern Hemisphere. This unusual appearance of a "northern" pygmy right whale demonstrates that the biogeography of extant species is remodeling over time instead of unchangeable distribution as fossils are often found outside the recognized distribution showing how evolution is at work. Together with the current understanding of climate change and anthropogenic impact upon the globe, this unexpected find calls for more detailed studies, in particular into remote or commonly neglected areas to monitor how marine mammals are responding to global change.

\section{Acknowledgements}

We thank Bengt Larsen for photographing the Gambia whale; Tom Arnbom for presenting the occurrence of the Gambia Caperea to JGM; National Museum of New Zealand for allowing dissection of the stillborn Caperea led by Ewan Fordyce; Moyna Müller for the Caperea illustration shown in Fig. 2; Ewan Fordyce for encouraging and discussing this study; the editors Shigeru Kuratani and Hiroshi Kajihara for helpful guidance; Olivier Lambert and an anonymous reviewer for constructive comments.

\section{Funding}

CHT was financially supported by a Startup Fund at the National Taiwan University. 


\section{Availability of data and materials}

The correspondence between Tom Arnbom and JGM in 1995 indicating that the whale was found on the beach of Gambia, Africa, can be found in the Supporting Information.

\section{Authors' contributions}

CHT participated in data analysis and design of the study and drafted the manuscript; JGM collected data; CHT and JGM coordinated the study and revised the manuscript. Both authors gave final approval for publication.

\section{Ethics approval and consent to participate}

Not applicable.

\section{Consent for publication}

Not applicable.

\section{Competing interests}

The authors declare that they have no competing interests.

\section{Publisher's Note}

Springer Nature remains neutral with regard to jurisdictional claims in published maps and institutional affiliations.

\section{Author details}

'Department of Life Science, National Taiwan University, Taipei 10617, Taiwan. ${ }^{2}$ Department of Vertebrate Zoology, National Museum of Natural History, Smithsonian Institution, Washington, D.C. 20013-7012, USA.

Received: 5 July 2018 Accepted: 7 December 2018

Published online: 17 December 2018

\section{References}

1. Jefferson TA, Webber MA, Pitman RL. Marine mammals of the world. 2nd ed. London: Academic Press; 2015.

2. Kemper C. Family Neobalaenidae (pygmy right whale). In: Wilson DE, Mittermeier RA, editors. Handbook of the mammals of the world. Barcelona: Lynx Edicions; 2014. p. 214-20.

3. Bisconti M. Comparative osteology and phylogenetic relationships of Miocaperea pulchra, the first fossil pygmy right whale genus and species (Cetacea, Mysticeti, Neobalaenidae). Zool J Linnean Soc. 2012;166:876-911.

4. Buono MR, Dozo MT, Marx FG, Fordyce RE. Late Miocene potential neobalaenine mandible from Argentina sheds light on the origins of the living pygmy right whale. Acta Palaeontol Pol. 2013:59:787-93.

5. Fitzgerald EMG. Possible neobalaenid from the Miocene of Australia implies a long evolutionary history for the pygmy right whale Caperea marginata (Cetacea, Mysticeti). J Vert Paleontol. 2012;32:976-80.

6. Tsai C-H, Collareta A, Fitzgerald EMG, Marx FG, Kohno N, Bosselaers M, Insacco G, Reitano A, Catanzariti R, Oishi M, Bianucci G. Northern pygmy right whales highlight quaternary marine mammal interchange. Curr Biol. 2017;27:R1058-9.

7. Ross G, Best P, Donnelly B. New records of the pygmy right whale (Caperea marginata) from South Africa, with comments on distribution, migration, appearance, and behavior. J Fish Can. 1975;32:1005-17.

8. Mead JG, Mitchell ED. Atlantic gray whales. In: Jones ML, Swartz SL, Leatherwood S, editors. The gray whale Eschrichtius robustus. London: Academic Press; 1984. p. 33-53.

9. Bisconti M. Morphology and phylogenetic relationships of a new eschrichtiid genus (Cetacea: Mysticeti) from the early Pliocene of northern Italy. Zool J Linnean Soc. 2008;153:161-86.

10. Bisconti M, Varola A. The oldest eschrichtiid mysticete and a new morphological diagnosis of Eschrichtiidae (gray whales). Rivista Ital Paleontol Strat. 2006;112:447-57.

11. Ichishima H, Sato E, Sagayama T, Kimura M. The oldest record of Eschrichtiidae (Cetacea: Mysticeti) from the late Pliocene, Hokkaido. Japan. J Paleontol. 2006;80:367-79.

12. Tsai C-H, Boessenecker RW. An Early Pleistocene gray whale (Cetacea: Eschrichtiidae) from the Rio Dell Formation of Northern California. J Paleontol. 2015;89:103-9.

13. Tsai C-H, Fordyce RE, Chang C-H, Lin L-K. Quaternary fossil gray whales from Taiwan. Paleontol Res. 2014;18:82-93.
14. Whitmore F, Kaltenbach J. Neogene Cetacea of the Lee Creek phosphate mine, North Carolina. Virginia Museum of Natural History Special Publication. 2008;14:181-269.

15. Elwen SH, Gridley T. Gray whale (Eschrichtius robustus) sighting in Namibia (SE Atlantic)-first record for Southern Hemisphere. International Whaling Commission document SC/65a/BRG30. 2013:1-5.

16. Glover KA, Kanda N, Haug T, Pastene LA, Øien N, Goto M, Seliussen BB, Skaug HJ. Migration of Antarctic minke whales to the Arctic. PLoS One. 2010;5:e15197.

17. Stone G, Florez-Gonzalez L, Katona S. Whale migration record. Nature. 1990;346:705

18. Pyenson ND. The high fidelity of the cetacean stranding record: insights into measuring diversity by integrating taphonomy and macroecology. Proc. R. Soc. B. 2011;278:3608-3616

\section{Ready to submit your research? Choose BMC and benefit from:}

- fast, convenient online submission

- thorough peer review by experienced researchers in your field

- rapid publication on acceptance

- support for research data, including large and complex data types

- gold Open Access which fosters wider collaboration and increased citations

- maximum visibility for your research: over $100 \mathrm{M}$ website views per year

At $\mathrm{BMC}$, research is always in progress.

Learn more biomedcentral.com/submissions 